\title{
WALKING IN THE WINTER: A QUALITATIVE STUDY TO IDENTIFY ENVIRONMENTAL BARRIERS ENCOUNTERED BY SENIORS.
}

\author{
By:
}

\section{Herthana Siva}

B.ES. (hons) University of Waterloo, 2011

\author{
A Major Research Paper \\ Presented to Ryerson University \\ In partial fulfillment for the degree of \\ Master of Planning \\ In \\ Urban Development
}

Toronto, Ontario, Canada, 2013

(c) Herthana Siva, 2013 


\section{Author's Declaration}

I hereby declare that I am the sole author of this Major Research Paper.

This is a true copy of the Major Research Paper, including any required final revisions, as accepted by my examiners I authorize Ryerson University to lend this paper to other institutions or individuals for the purpose of scholarly research.

I further authorize Ryerson University to reproduce this Major Research Paper by photocopying or by other means, in total or in part, at the request of other institutions or individuals for the purpose of scholarly research. I understand that my Major Research Paper may be made electronically available to the public. 


\title{
WALKING IN THE WINTER: A QUALITATIVE STUDY TO IDENTIFY ENVIRONMENTAL BARRIERS ENCOUNTERED BY SENIORS.
}

\author{
(c) Herthana Siva, 2013 \\ Master of Planning in Urban Development \\ Ryerson University
}

\begin{abstract}
The purpose of this research was to explore features in the built environment that are considered to be barriers by seniors when walking in the winter. Nine seniors across four neighbourhoods in the City of Mississauga participated in the study. A combination of photovoice and semi-structured interviews was used to collect data. Findings revealed safety related to fall hazards and traffic conditions as major concerns among the seniors. Participants provided suggestions for potential changes to improve walking conditions for seniors, including: judicious placement of interim crosswalks, more open public washrooms, additional benches in parks, and railings along sloping sidewalks and cameras in parks. This research contributes to the limited literature that investigates the role of the built environment on physical activity levels among seniors. Results can help inform questions for the development of a walkability audit tool, public health promotion strategies and municipal land use policies to build healthy communities.
\end{abstract}

Keywords: healthy communities, public health, planning, built environment barriers, aging population. 


\section{Acknowledgements}

I would like thank my supervisor, Dr. Raktim Mitra for his advice, support and encouragement. The comments and suggestions Dr. Mitra provided has been invaluable to this research study. I would like to also thank my second reader Sharon Williams from the Region of Peel Public Health for taking the time to review and provide comments to my research report.

I would like to thank Sara Stinson, supervisor at the Mississauga Seniors' Centre. Mrs. Stinson and the staff at the Seniors' Centre made me feel welcome and continuously provided me with help throughout my stay at the centre.

I would like to express my sincere appreciation to all of the individuals who agreed to take part in this study. This project could not have been possible without their generous support and commitment. I would like to finally thank my Dad. His support and patience helped me through all of the long winter mornings at the Seniors' Centre. 


\section{TABLE OF CONTENTS}

\section{Chapter One: Introduction}

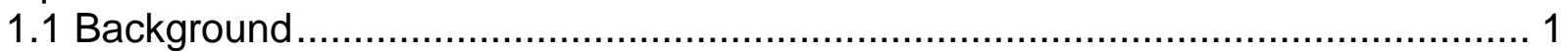

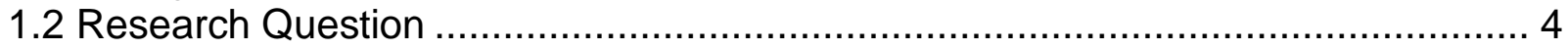

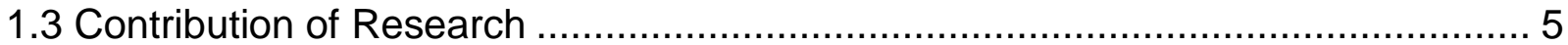

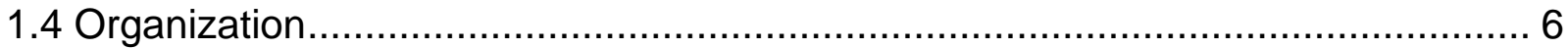

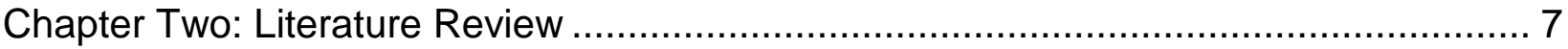

Chapter Three: Research Method

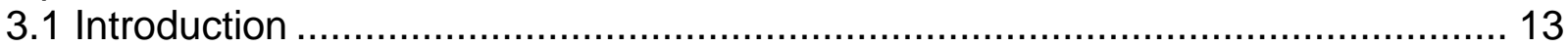

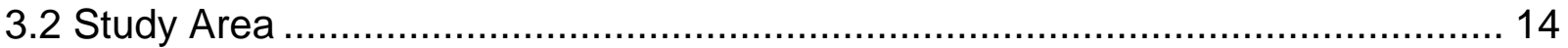

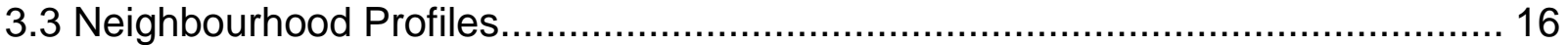

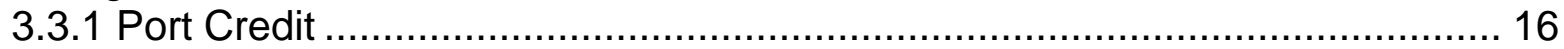

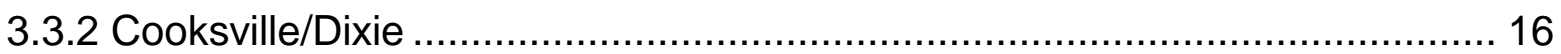

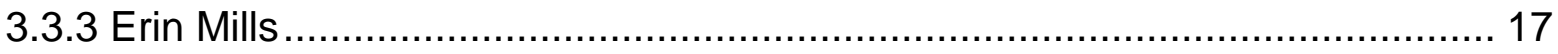

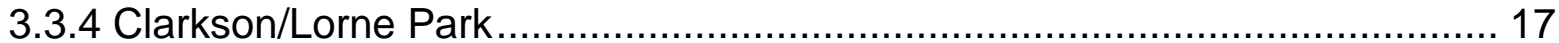

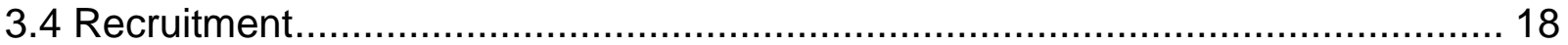

Chapter Four: Findings

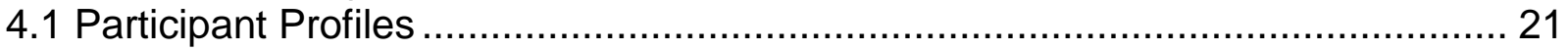

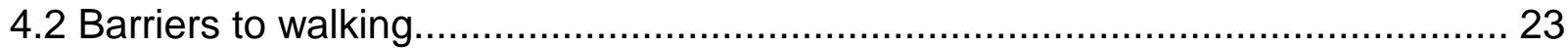

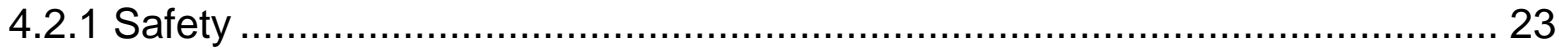

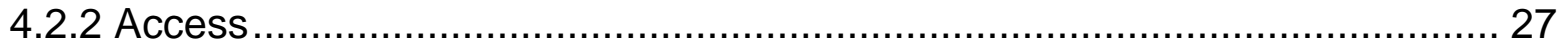

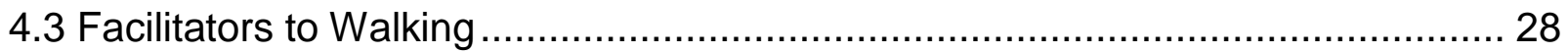

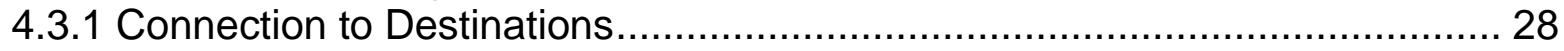

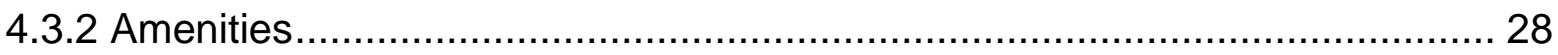

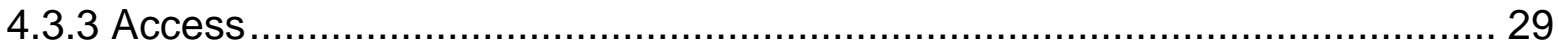

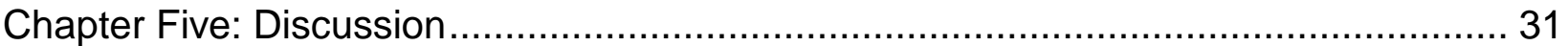

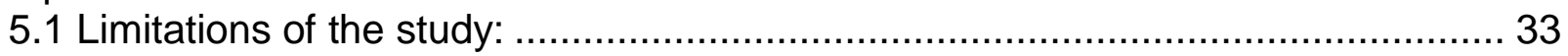

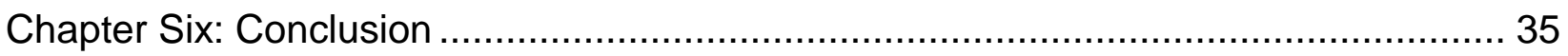

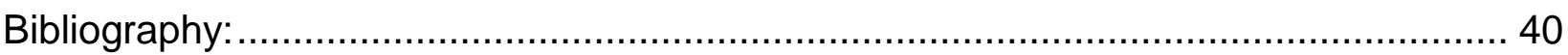




\section{LIST OF TABLES}

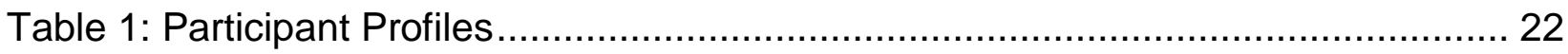




\section{LIST OF FIGURES}

Fig. 1: Region of Peel Map and City of Mississauga Neighbourhood Map ................... 15

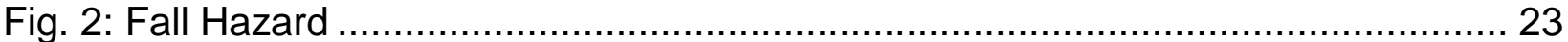

Fig. 3: Lack of Sidewalk and Heavy Traffic............................................................... 24

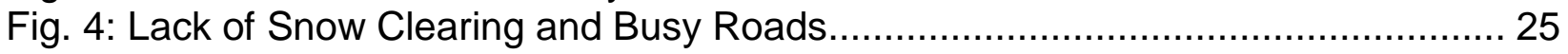

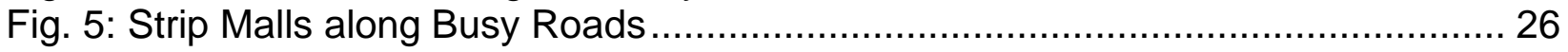

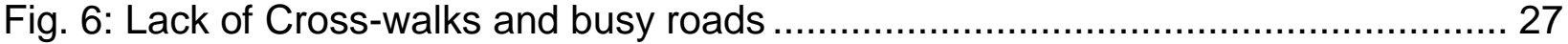




\section{LIST OF APPENDICES}

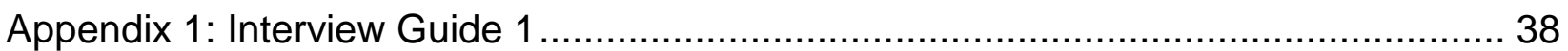




\section{Chapter One: Introduction}

\subsection{Background}

The population in Canada is rapidly aging. Between 2006 and 2011 the number of Canadians aged 65 and over increased $14.1 \%$ to nearly 5 million (Martel \& Menard, 2013). Older Canadians are living longer than previous generations, with the life expectancy for females at 83 years and for males 79 years (Statistics Canada, 2012; Edwards \& Mawani, 2011). However, according to recent evidence, $50 \%$ of senior men and $64 \%$ of senior women are inactive (Statistics Canada, 2009).

It is important for seniors to engage in physical activity that is moderate-intensity to mitigate the chances of chronic illnesses such as heart disease, high blood pressure and diabetes, and maintain an improved quality of life. Furthermore, undertaking regular physical activity helps maintain mobility through improved joint function, flexibility, muscle and bone strength, which reduces the risk of falls and injuries (Edwards \& Mawani, 2011; Health Canada, 2002; Lim \& Taylor, 2005; Coleman \& Walker, 2004). Public Health of Canada 2010 report on the State of Public Health in Canada states that fall related injuries are the most common cause of injuries among seniors, as one in three seniors is likely to fall at least once each year (Public Health Agency of Canada, 2010). Fall related injuries to seniors have a significant economic implication on the Canadian health-care system (Scott et al, 2004). In addition, the experience of fall may relate to social isolation, depression, loneliness, dependence and limited mobility of seniors, adding more burden to the health care system (Public Health Agency of 
Canada, 2010). There are a number of factors that contribute to the high number of seniors that experience falls each year, including the lack of physical activity (Public Health Agency of Canada, 2010).

Public health professionals are increasingly focusing their attention on developing policy frameworks that seek to address health issues through interventions in the built environment (Region of Peel, 2011). In Ontario, the provincial government is developing overarching policy frameworks and objectives that ensure new development takes into consideration the health of its community members (Region of Peel, 2011). The Planning Act and the Provincial Policy Statement (2005) provide high-level policy direction to local municipalities in Ontario to include in their Official Plans (OP) policies that seek to develop communities that promote healthy, active, liveable, safe communities (Region of Peel, 2011).

With regard to practice, several regional governments and local municipalities are requiring health background studies from developers, which outlines the health implications of a development, and are creating healthy development indexes (Region of Peel, 2011). These tools are emerging as ways to ensure that the planning process for new development takes into consideration the health implications of a new designed community (Region of Peel, 2011). Furthermore, community walkability/environment audit tools are being developed by municipalities to be used by community members in order to enable physical activity in their communities (Hoehner et al, 2006). This relatively new tool provides policymakers with an understanding of the physical 
environment in a particular neighbourhood in order to create policies to improve the built environment and evaluate the progress in meeting the needs of individuals in their municipality (Tencer et al, 2010; Hoehner et al, 2006). An improved understanding of the built environment-related enablers and barriers to walking can be highly valuable in informing such policies.

Research has demonstrated that seniors prefer walking as a form of physical activity, as well as a means to travel independently (Chaudhury et al, 2011; Nagel et al, 2008; Stahl et al, 2008). However, barriers in the outdoor physical environment such as a lack of safe accessible and affordable outdoor community space, inaccessibility to washrooms, lack of ramps to parks, unsafe infrastructure, poorly lit areas, adverse weather, are major challenges and can inhibit walking and other forms of physical activity amongst the senior population (Chaudhury et al, 2011; Public Health Agency of Canada, 2010; CFLRI, 2005). Ensuring that seniors' have a supportive physical and social environment can enable them to live an active and social lifestyle.

However, existing research investigating the barriers in the built environment for seniors when walking in their neighbourhood is limited. In particular, elderly walking behaviour in winter months has not been examined extensively. One notable study was undertaken by Toronto Rehab's Winter Research Group (Toronto Rehab, 2011). Using specialty cameras, researchers identified sidewalks where seniors were experiencing the most falls, had curb cuts that did not allow for proper drainage. The final report by Toronto 
Rehab is now before Toronto City Council, and advocates for the alteration of curb cuts, and longer cross-walk times (Toronto Rehab, 2011). Further studies are needed to expand the current research on the effect of weather on walking among the senior population. This is an important gap in the current literature because environmental hazards and barriers may be different during the winter months compared to summer or fall. The combination of cold, snow, and decreased light levels may heavily influence walking patterns and speed amongst individuals.

\subsection{Research Question}

In order to improve current understanding of the barriers to walking among older adults, this research examined the walking behaviour of older adults living in the City of Mississauga, Ontario. In particular, the following research question was explored:

What features of the neighbourhood built environment act as barriers and enablers for seniors' walking in the winter months?

Handy et al (2002) define the "built environment" as a composition of urban design, land use, and the transportation system, and encompasses patterns of human activity within the physical environment. Furthermore, "barriers" is attributed to the perceived risk associated with undertaking a specific activity, inhibiting the individual from undertaking the task. Additionally, "winter months", for the purposes of this research study, will be between January and February. The average winter temperature in January and 
February for residents in the City of Mississauga is approximately $-6^{\circ} \mathrm{C}$ with an average snowfall of $26.5 \mathrm{~cm}$ (City of Mississauga, 2013; The Weather Network, 2013).

\subsection{Contribution of Research}

This study will contribute to and expand on the current knowledge of environmental barriers faced by seniors when walking in a winter context. This research provides a small sample of experiences of seniors walking behaviour and the barriers found in the built environment in various neighbourhoods in the City of Mississauga, Ontario. The findings from this research study have potential to directly contribute to urban policy. For example, the results can inform the development of a community walkability audit tool for the City of Mississauga. Walkability tool is an emerging approach to planning that promotes community member advocacy for the changes individuals want to see to their neighbourhood. As such, this research will provide information from the perspective of an individual, allowing for the development of a community walkability audit tool that is self-explanatory and requires little formal training to the community auditor (Hoehner et al, 2007). 


\subsection{Organization}

The report has been organized in the following chapters. Chapter two is a literature review that was conducted in order to gain a better understanding of the current research that exists linking the influence of the built environment and physical activity levels. Chapter three describes the research method. Chapter four outlines the findings from the collected data to reveal themes that emerged from the research process. Chapter five is the discussion of findings from the study, which is related back to the previous findings in literature review. Implications and recommendations are discussed. Finally, chapter six is the conclusion whereby the findings from the research report are summarized. Furthermore, the limitations and directions for future research direction are also outlined. 


\section{Chapter Two: Literature Review}

A literature review was conducted to explore the current research on the influence of the built environment on physical activity and walking levels, with particular emphasis on older adults. Both urban planning and public health literature was consulted to gain a better understanding of this field of research.

An emerging field of research in public health and urban planning links the physical design of communities and its influence on physical activity and travel patterns (Frank et al, 2003; Giles-Corti \& Donovan, 2003; Handy et al, 2002; Sallis et al, 1998). The suburbanization of our communities has separated the locations of where we live, work and play. The private vehicle has become the main mode of transportation and has reduced the need to walk and bicycle to destinations within our community (Frank et al, 2003). Public health professionals, since World War II have promoted the need for individuals to engage in physical activity, and encouraged incorporating walking as part of a daily routine (Frank et al, 2003). Researchers, professionals and community-based organizations are now looking at how an individual's neighbourhood can play a major role in how they can promote increasing physical activity (Pikora et al, 2006; Frank et al, 2003). 
Of particular interest for this research is the growing body of literature that explores the importance of the built environment enabling physical activity amongst older adults.

This literature explores the physical and social environment factors that either inhibit or facilitate walking among older adults. Public health studies have explored how increasing exercise, including walking, can delay the onset of dementia and Alzheimer disease (Larson et al, 2006; Weuve, 2004), obesity in older adults (King et al, 2011) and increase in quality of life (Patterson et al, 2004). Based on the reviewed literature in public health and emerging research in urban planning, there is a clear link between the design of the outdoor physical environment and physical activity levels (King et al, 2005; Li et al, 2004; Berrigan et al, 2002; Ball et al, 2001).

Although there is a significant amount of research which associates the built environment to physical activity levels, the current understanding of the influence of the built environment on elderly walking is limited (Cunningham \& Michael, 2004). A common theme found in studies is the presence of environmental hazards in the built environment that are perceived as fall risks, preventing or seriously challenging seniors from utilizing a certain spaces in their community (Chaudhury et al, 2011; Stahl et al 2008; Lockett et al, 2005; Gallagher \& Scott, 1997).

Lockett et al (2005) conducted an exploratory qualitative study using photovoice to explore the environmental factors that influence the walking choices amongst seniors in Ottawa, Ontario. They found that the majority of seniors regarded "traffic and fall hazards" to be the biggest barriers to walking. Traffic hazards seniors were concerned 
about included: being hit or splashed by a car, traffic lights in inconvenient locations which forced them jaywalk or walk long distances to get to their desired location. Fall hazards included areas with no sidewalks or sidewalks that were uneven, cracked, which presented dangerous walking conditions for seniors who required a walking aid. The participants in this study also regarded the importance of benches and washrooms as important features that would improve their walking experience (Lockett et al., 2005). The study concluded with suggestions of an increased need for inter-disciplinary collaboration between the health, planning, engineering, policy professions to ensure positive changes occur in the built environment for seniors.

Chaudhury et al (2011) compared high and low density neighbourhoods to examine the influences in the physical and social environmental factors on walking activity levels. The study took place in high-density neighbourhoods in Metro Vancouver and lowdensity neighbourhoods in Metro Portland, Oregon. The authors used photovoice and focus groups to collect data. Findings were categorized into four major themes, Safety and Security, Accessibility, Comfort of Movement, and Peer Support. Most seniors expressed concerns about the maintenance and upkeep of the physical environment, regardless of neighbourhood density. Seniors mentioned uneven sidewalks, tripping hazards; narrow sidewalks and the absence of sidewalks are obstacles and barriers to their walking environment. Seniors in the higher-density neighbourhood also reported more traffic related issues compared to those living in low density neighbourhoods. Traffic related concerns included high traffic volume, unsafe intersections and 
crosswalks, and poor visibility. Seniors in both high and low-density neighbourhoods often stated the importance of having amenities such as parks, banks, grocery stores, drug stores nearby their home. Comfort of movement was also important; all participants identified the availability of seating, railings, handrails, ramps, safe stairs, and water fountains as features that facilitated to physical activity (Chaudhury et al, 2011).

Stahl et al (2008) explored ways in which to increase accessibility and safety for seniors in the outdoor environment in a medium-sized town in Southern Sweden. The results were similar to the findings by Chaudhury et al (2011) and Lockett et al (2005); however, the elderly participants in this study were able to identify a variety of more specific improvements they wanted to see, such as: improved dispersion of traffic, improved signposts, separation of cyclists and pedestrians, longer crossing time across crosswalks and improved snow removal.

Other studies that have explored the relationship between the built environment and walking among the senior population have taken a quantitative approach. Li et al (2005) studied older adults in 56 city-defined neighbourhoods in Portland, Oregon, to examine walking activity at both neighbourhood level and resident level. The researchers undertook a cross sectional, multilevel study of senior residents. Residents were surveyed on their level of walking in their neighbourhood. The results from this study clearly linked to walking patterns to specific neighbourhood built environment characteristics. Li et al (2005) found neighbourhoods with high levels of employment and household density, greater number of street intersections; green and open spaces for 
recreation were significantly associated with higher levels of walking activity. The findings from this study indicate that walking in neighbourhoods was higher when residents believed that they were in close proximity to recreational facilities and felt safe when walking.

Nagel et al (2008) undertook a similar study that extends the work conducted by Li et al (2005), in Portland, Oregon. Nagel et al (2008) objectively measured the characteristics in neighbourhoods and walking activity. A multilevel regression analysis was used to determine the association between built environment and walking behaviour. Nagel et al (2008) found that seniors who reported walking, there was a significant relationship between proximity to and number of destinations, such as commercial and retail establishments. Also, it was there was an increase in walking along high traffic volume streets.

A study conducted by Booth et al (2000) examined social-cognitive and perceived environmental influences associated with physical activity amongst older Australians. The authors administered surveys and undertook logistic regression modeling to identify results that found a significant relationship between seniors who considered themselves active and inactive. The researchers found the physical environment including safe footpaths, access to a recreation centre, bike path, park, golf course and swimming pool as important elements of the built environment that influenced seniors' physical activity. 
Furthermore, a supportive social environment with physically active partners and family members are associated with seniors being active.

The review of literature revealed a number of barriers seniors encounter in the built environment when walking. The theme of safety including physical safety due to poor maintenance of sidewalks and trails, and traffic hazards were considered the most common concern. Seniors' mentioned uneven, cracked sidewalks that is too narrow as fall hazards. Traffic hazards included a fear of being hit, high traffic volumes, and high vehicle speeds, and unsafe intersections. Furthermore, studies found seating, washrooms, railings, ramps, and water fountains as providing more comfort to seniors when walking in their neighbourhood. Accessibility to local amenities such as parks, recreational facilities, local grocery stores and banks were also seen as important to walking amongst seniors. Although literature identifying environmental barriers associated with the movement of seniors' in their respective communities is growing, very few studies have explored senior mobility issues in the winter. 


\section{Chapter Three: Research Method}

\subsection{Introduction}

A photovoice approach was used to collect data for this research. Photovoice is a branch of Participatory-Action Research (PAR), where participants take photos to document their experience in the field of study. Semi-structured interviews were conducted to supplement the photos. Hall (1994) described participatory research as a process that combines three activities: research, education, and action. Park (1994) indicates that participatory research seeks to form a partnership with ordinary people with problems who are empowered to share their experience with a researcher, as opposed to the traditional research model with a primary investigator seeking data from subjects through questionnaires, interviews, and experiments. Photovoice falls under this form of research, as it is a method that values the knowledge put forth by people, seeks to identify what the community regards as important, and shares experiences through images of people that may not be heard otherwise (Chaudhury et al, 2012). Lockett et al (2005), used photovoice in their research and stated photovoice not only enabled them to understand the broader environment and the linkages between the reported destinations, but the participants enjoyed having control of photographing their environmental hazards.

One of the unique advantages of this form of research is its flexibility to be adapted to meet specific participatory goals and distinctive public health issues (Wang and Burris, 1997). Photovoice uses the visual image as the main communication tool to allow the 
participant to record moments and ideas that may otherwise not be revealed through an interview. The image is the conduit for the participant to reveal through a facilitated discussion moments and ideas that may not be available otherwise. Finally, the use of photovoice may act as an educational tool that will aid in empowering the participant to effectively inform policymakers (Wang \& Burris, 1994), and possibly contribute to the development of a community walkability audit tool. Photovoice is a popular tool in health promotion and public health studies; however, there is a lack of literature that bridges planning and public health that utilizes this research method.

\subsection{Study Area}

This study was conducted in the City of Mississauga in the Region of Peel. The senior population in this region is expected to more than double in the next 20 years (Region of Peel, 2012). The number of seniors in 2031 is projected to be 294,880 , which will be $20 \%$ of the overall population in the region (Region of Peel, 2012).

Compared to the other two other municipalities in the region of Peel - City of Brampton

and the Town of Caledon - the City of Mississauga has the highest percentage of seniors, aged 65 and older. 

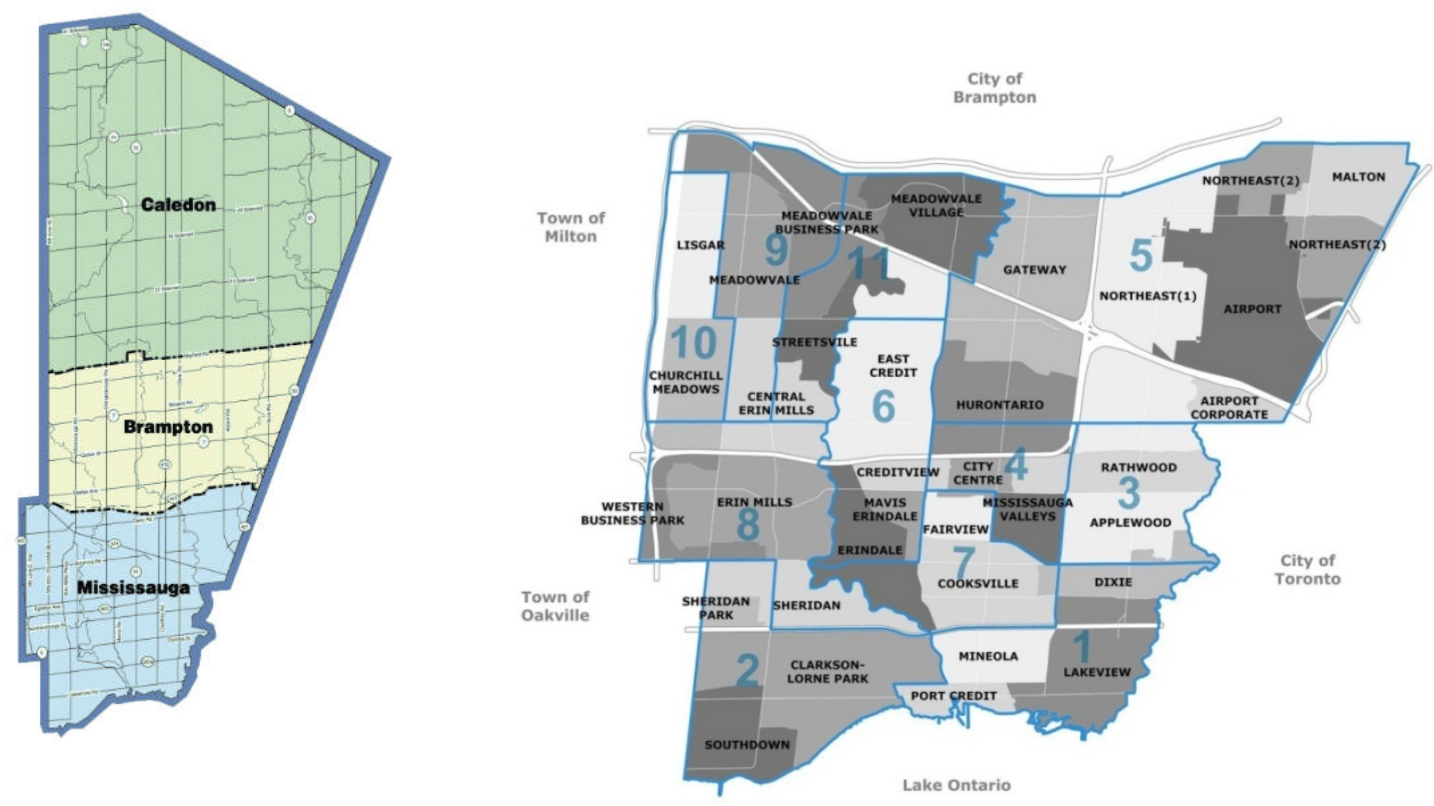

Fig. 1: Region of Peel Map and City of Mississauga Neighbourhood Map

Participants for the study currently reside in the following neighbourhoods: Port Credit, Erin Mills, Clarkson/Lorne Park, Cooksville/Dixie. The majority of participants were from the Port Credit area. A previous study reported that Port Credit neighbourhood had the highest proportion of seniors in the City with approximately $14.7 \%$ of all population, followed by Cooksville/Dixie with 13\%; Clarkson/Lorne Park 13\%. Erin Mills area has 10.4\% respectively (Senior Population in the Region of Peel, 2006). 


\subsection{Neighbourhood Profiles}

\subsubsection{Port Credit}

Port Credit is a well-established, functioning urban village located along the Lake Ontario/Credit River waterfront, the south-central area in the City of Mississauga. The population in Port Credit/Lakeview in 2006 was 32,005, with an average family income of $\$ 105,955$ (Portraits of Peel, 2006). It is considered a desirable place to live within the city, due to the natural beauty and walkable waterfront lined with shops, restaurants, and an active port and harbour, which also offers recreational activities such boating and fishing. Port Credit is known for numerous heritage homes that exist within its neighbourhoods and are reflective of its historical development patterns.

\subsubsection{Cooksville/Dixie}

Cooksville and Dixie districts are located in central and central-east in the City of Mississauga. The population size of this area in 2006 was 161, 560 with an average family income of $\$ 76,575$ (Portraits of Peel, 2006; City of Mississauga, 2009). Both Cooksville and Dixie have distinctive characteristics. Cooksville encompasses the City of Mississauga's municipal buildings, and is a desired placed to live as it is the centre for civic, industrial, and commercial interests including Square One (City of Mississauga Heritage, 2009). Cooksville has undergone major changes over the years, as new condo developments; including the "Marilyn Monroe" buildings have made the city and Cooksville a well-known area. Dixie is further divided into smaller neighbourhoods in Mississauga, such as Applewood Heights, an established residential community with retail centres to serve the community (City of Mississauga Data, 1999). 


\subsubsection{Erin Mills}

Erin Mills is located in the northwest area in the city. The population of Erin Mills in 2006 was 91,755 with an average family income of $\$ 107,508$ (Portraits of Peel, 2006). It is an established residential community that is home to Credit Valley hospital, schools, community centres, and shopping facilities. This area is predominately low density, with single-family detached homes. Recent developments particularly around the central Erin Mills node, which is in close proximity to a major mall, Erin Mills Town Centre, there is a mix of apartments, townhouses, office, and amenities (City of Mississauga, 2012). The population of Erin Mills in 2006 was 91, 755 with an average family income of $\$ 107,508$ (Portraits of Peel, 2006). Development in this area over in recent years has been rapid as it is a desired area to be in.

\subsubsection{Clarkson/Lorne Park}

The Clarkson/Lorne Park is a stable neighbourhood located in South-west Mississauga. The population in 2006 was 45, 965 and an average family income in 2005 of $\$ 140,808$ (Portraits of Peel, 2006). Clarkson/Lorne Park community is primarily low density residential with single detached homes. This area is stable and does not experience a significant amount of newer developments (City of Mississauga, 2009). 


\subsection{Recruitment}

The Mississauga Seniors Centre (MSC) was the primary location for the recruitment of seniors. The MSC is a recreational facility located in the southern part of Mississauga. The seniors' centre accommodates adults over the age of 60 and offers various exercise programs, special events, and educational courses (City of Mississauga, 2013). Data was also collected from the Community Centre located next to the MSC. Recruitment at the MSC took place for 2 weeks and at the Community Centre for one day. All the participants met the following criteria (1) were adults over the age of $60,(2)$ lived in the City of Mississauga, (3) had working knowledge of English, and (4) selfidentified themselves as capable walkers and walked at least one day in a week.

At the MSC the researcher set up an information table to showcase the study. Seniors were invited to take photographs of their perceived barriers when walking in the winter using a disposable camera and to share their walking experience in an interview. Interested participants were given a 27-exposure disposable camera, along with a project information sheet. Participants were contacted to collect the cameras after one to two weeks and an interview was scheduled to discuss the images they took. A total of seven seniors were recruited for the study from the MSC and two from the Community Center. Out of the nine participants seven were women and two men. All but one participant took pictures with the disposable cameras. 
The interviews took place at the MSC or the Community Centre once the pictures were developed and the participant was available. During the semi-structured interviews (Appendix 1), the first few questions were demographic, social and background questions that sought to understand their physical activity levels and general features of the built environment that the participants perceived as a hazardous to their walking. The next set of questions reflected the relationship between the participant's social environments and walking activity. The final set of questions was geared towards a discussion format that was centered on the images the participants were asked to take, including where and why they took the images. Participants reflected on each image and identified how the barrier portrayed in the image influenced their walking patterns in their neighbourhood. The discussions enabled the individuals to critically express their perceptions and concerns about their social and the built environment through reflecting on the images (Wang \& Burris, 1994). The interview was concluded with asking participants for any recommendations and improvements that would help overcome the barriers and improve their walking experience in their neighbourhood. The seniors' that undertook this research project were especially interested in the topic and were engaged from the beginning of the process. All interviews were audio taped for efficiency, and were transcribed for the qualitative analysis of the findings.

Next, the transcribed interview scripts were theme-coded for qualitative data analysis. A similar approach to the Chaudhury et al (2012) study was taken, in which the researcher utilized a deductive analytic strategy called "Successive Approximation" (Neuman, 2006). This strategy entails the researcher starting with a framework of concepts 
identified from the literature and moving between the collected data and the abstract concepts (Neuman, 2006). A framework developed by Neuman (2006) was followed to start coding the transcripts. First, from the reviewed literature, three common themes were identified that were related to the risk of falls and perception of walkability: (1) safety including physical infrastructure and maintenance of roads, (2) comfort of movement, and (3) access (Chaudhury et al, 2012; Lockett et al, 2005; Li et al, 2005; Booth et al, 2000). Second, the interview scripts were coded based on these identified themes. However, new themes also emerged from which resulted in assigning new codes to fit the data. Third, each participant was given a pseudonym in order to maintain confidentiality. Finally, the results were described. 


\section{Chapter Four: Findings}

\subsection{Participant Profiles}

Semi-structured interview data collected from nine older adults in Mississauga, ON, were analyzed to determine the neighbourhood level barriers to walking. Sociodemographics of the participants were collected during the interview (Table 1). Seven out of the nine participants were female (77\%). The age range for all participants was 60 to 88. The average age for females was 66 and for the males was 83. Five participants lived with a spouse (55\%) and three (33\%) lived alone. Seniors were recruited from various areas within the City of Mississauga. While the five out of the nine participants (55\%) lived in the Port Credit Area, other participants lived in the Erin Mills, Clarkson/Lorne Park, and Cooksville/Dixie. All participants were physically active as most participated in more than one exercise class at the seniors' or community centre. Eight of the nine (88\%) seniors walked to supplement exercising and incorporated walking as much as possible in their routine. 
Table 1: Participant Profiles

\begin{tabular}{|c|c|c|c|c|}
\hline District in Mississauga & $\begin{array}{l}\text { Port } \\
\text { Credit }\end{array}$ & $\begin{array}{l}\text { Erin } \\
\text { Mills }\end{array}$ & $\begin{array}{l}\text { Cooksvillel } \\
\text { Dixie }\end{array}$ & Clarkson \\
\hline \multicolumn{5}{|l|}{ Gender } \\
\hline Male & & & 1 & 1 \\
\hline Female & 5 & 1 & 1 & \\
\hline Total & 5 & 1 & 2 & 1 \\
\hline \multicolumn{5}{|l|}{ Age (years) } \\
\hline \multicolumn{5}{|l|}{ Range $60-88$} \\
\hline $60-64$ & 2 & & & \\
\hline $65-69$ & 2 & 1 & 1 & \\
\hline \multicolumn{5}{|l|}{$70-74$} \\
\hline $75-79$ & 1 & & & 1 \\
\hline \multicolumn{5}{|l|}{$80-84$} \\
\hline $85-89$ & & & 1 & \\
\hline \multicolumn{5}{|l|}{ Living Arrangement } \\
\hline With Spouse (husband/wife) & 3 & 1 & & 1 \\
\hline Alone & 2 & & 1 & \\
\hline With Family & & & 1 & \\
\hline \multicolumn{5}{|c|}{ Number of times a week walked summer and winter } \\
\hline Everyday & 5 & & & \\
\hline 5 to 6 days & 1 & & & \\
\hline 3 to 4 days & 2 & & & \\
\hline 2 days & 1 & & & \\
\hline
\end{tabular}

Data was analyzed to discover the themes from the interviews and descriptions of the photographs. Safety was considered a major barrier when choosing where to walk in their neighbourhood in the winter. The issue of access also emerged as a theme that was considered a barrier. Seniors also provided recommendations to improve their walking environment including: addition of public washrooms and benches that enhanced comfort of movement through trails and pathways, addressing personal safety concerns, and access to local grocery stores and banks. Finally, the major theme that was discovered as the facilitator for walking among the seniors was continuous walking routes to parks and other open spaces. The remainder of this chapter describes the results related to the barriers and enablers of walking. 


\subsection{Barriers to walking}

\subsubsection{Safety}

All participating seniors took photographs that related to safety. Fall and traffic hazards were two of the main safety related concerns that were frequently reported. Fall hazards include the physical maintenance and clearing of the sidewalks, pathways, and trails they walk on a daily basis. Traffic hazards include having to walk on the road due to lack of sidewalks available, noisy and busy roads, lack of or inconvenient placement of crosswalks and conflicting pedestrian and vehicle traffic flow. Of particular concern were the absence of sidewalks and poor sidewalk conditions (e.g., uneven, sloping, cracked, slippery, icy sidewalks) that seniors encountered as obstacles on their walks. In addition, cracked pathways with potholes in parks were particularly hazardous during winter, as water would freeze forcing seniors to carefully navigate along the grass (Rose,Fig. 2).

\section{Fig. 2: Fall Hazard}

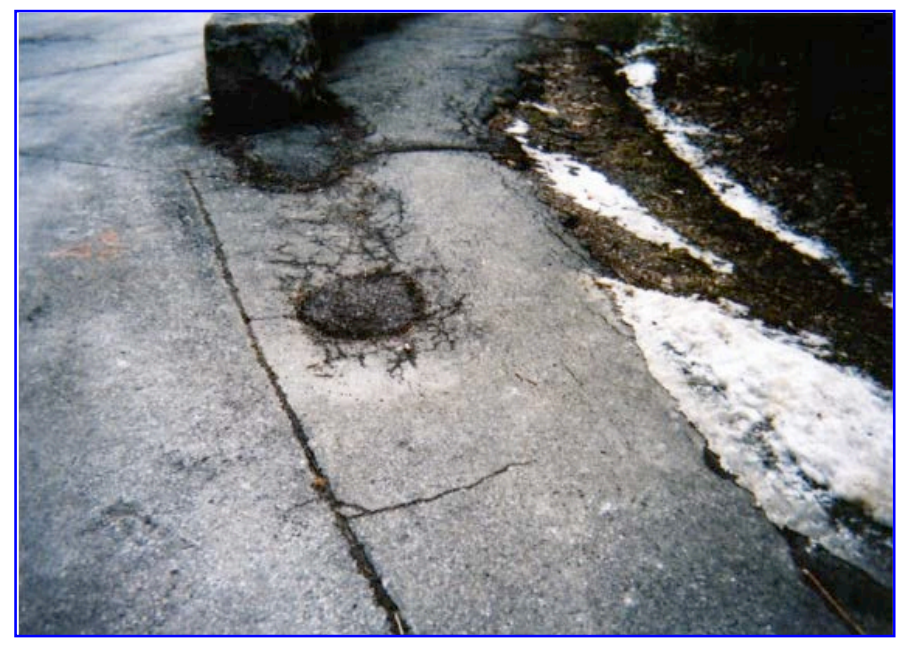

"Well, potholes (are fall barriers).

Dry weather I can usually go around them. When it rains, they gather water so it's not only the hole itself but the whole area (because) is going down, so it's like a huge swimming pool here, instead of a walking area." Rose, 69 
Kim, aged 62 described her experience walking her dog in her neighbourhood during the winter months:

"My neighbourhood doesn't have any sidewalks. It is low-density neighbourhood. So it's normally okay. Except when it snows and there is not enough room and some of the cars, sort of a little scared because they might not be able to stop, turning corners. In the wintertime I think definitely ice, sidewalks not being cleared makes it really difficult because I am walking my dog and all of a sudden there is one house didn't clear sidewalk, so I end up having to walk in the street." Kim, 62

Mary, aged 75, in good health and walks every day, described her favourite walking trail she has to be particularly careful as the trail consistently breaks off at points into neighbourhoods that do not have sidewalks forcing her to walk on the road with traffic and construction (Fig. 3).

\section{Fig. 3: Lack of Sidewalk and Heavy Traffic}

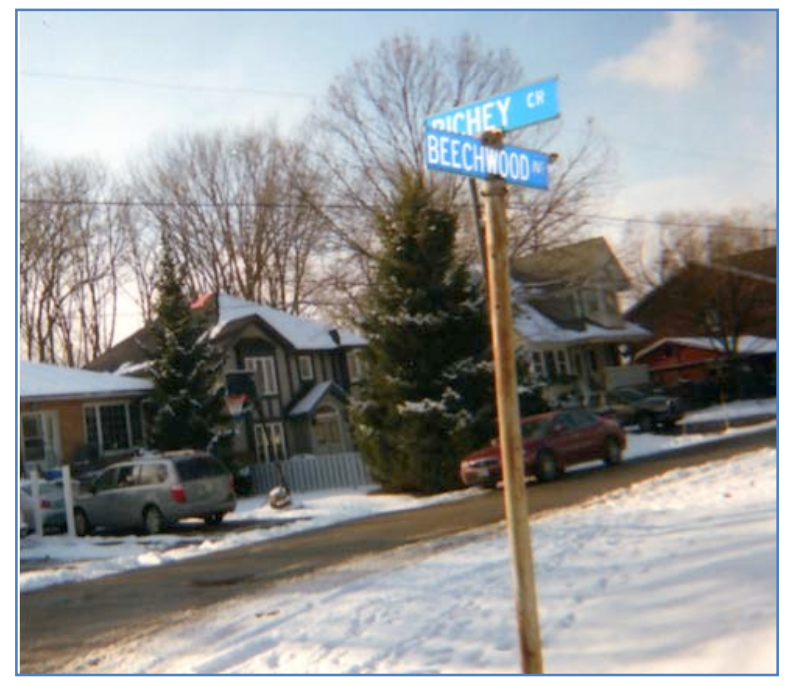

"The Waterfront Trail breaks off at Beechwood and walkers have to use the street. Most of streets do not have sidewalks, so walkers must walk on the streets, which have buildup of snow and ice closer to the curb. You have to be very careful." Mary, 75 
All nine of the seniors expressed that the maintenance of these sidewalks and pathways were important to their daily walking. Three seniors expressed concern and identified areas in the city where due the location of a gas station or a strip mall along a busy road was particularly hazardous to pedestrians. Seniors stated that drivers often lack awareness designated entry points to gas stations or plazas and do not pay particular attention to seniors.

Tony, aged 78, indicated how he had to walk through a busy gas station due to the city not clearing the sidewalk where vehicles coming from all directions. Furthermore, Emily, aged 60 , identified a sidewalk that was a fall hazard and a traffic hazard, presenting a particularly treacherous area to walk (Tony, Fig. 4 \& Emily, Fig. 5).

Fig. 4: Lack of Snow Clearing and Busy Roads

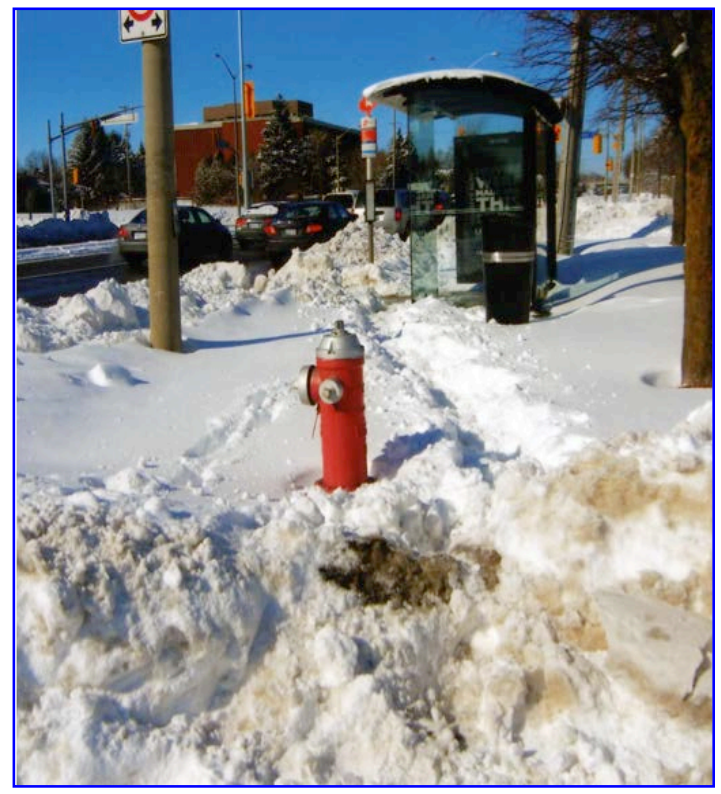

"This is a busy corner with lights and a bus stop. The only way people can get to that bus stop shelter is through this (snowy) path or on the road but you cannot walk safely. I didn't want to go to the bus shelter, I wanted to continue home but the only way you could do that is through a gas station. There are three/four pumps and people are coming in from all directions." Tony, 78 


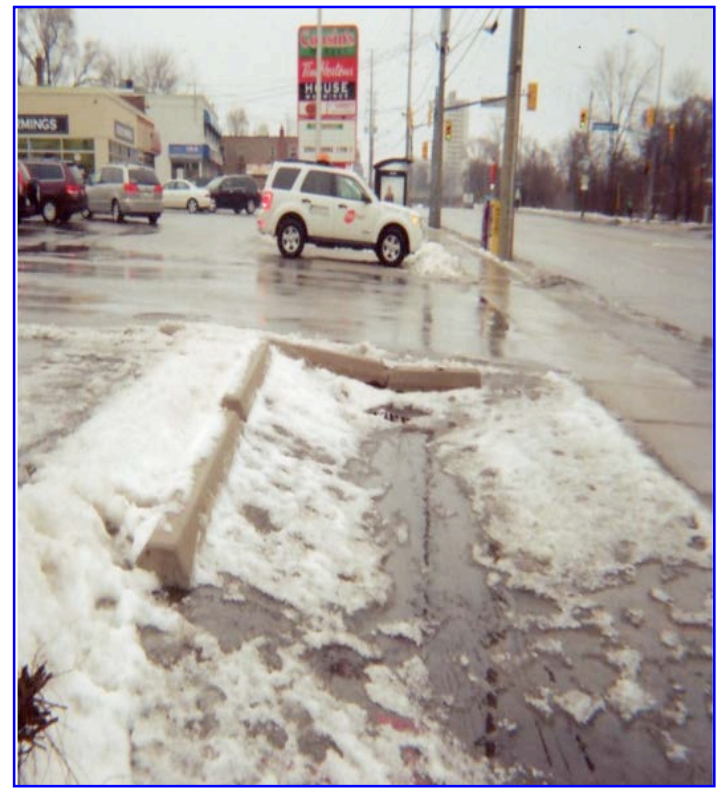

"If you are walking it is pretty slippery, not very well maintained. If you are walking into this (plaza), along the sidewalk. A lot of people are driving out and going in, and nobody is looking for pedestrians. I have actually been hit there. This was quite a few years ago. I was walking along the sidewalk and somebody sitting on the road, they were wanting to turn right and not looking. I thought he saw me but then he got the gas ready to turn right and then boom he hit me."Emily, 60

Personal safety was also an issue that was common amongst the participating seniors. Majority of seniors expressed they were particularly weary about walking through pathways in parks in the evenings or parks were heavily planted with bushes, feeling isolated or secluded.

A Patrick, aged, 88 who particularly enjoys walking through a park near his home expressed concern over a recent planting of bushes along a creek.

"Somebody a few years past thought to make it (the park) a nature reserve and they planted a few bushes there and now you can't see the creek. I think they should remove the brush so that you can see the creek. A lot of kids walk through the park. In the fall people could hid in there and attack you. It is something that is in the back of my mind." Patrick, 88 


\subsubsection{Access}

Two seniors identified areas in their neighbourhoods where a strip plaza was located, however due to the long distance between or lack of crosswalks they would have to traverse across roads with heavy traffic and wide lanes with a strip plaza.

Kim, aged 62, describes how a lack of crosswalks makes accessing nearby stores difficult:

"Along Lakeshore I found that there is a long distance between two traffic

lights and you see the store across. The inkling is to run across and try to cross the street. Because otherwise you would be backtracking, almost half a kilometer, in order to go back." Kim, 62

Jane, aged 67, described crossing the road to reach a trail that runs along the river as especially dangerous (Jane, Fig. 5).

Fig. 6: Lack of Cross-walks and busy roads

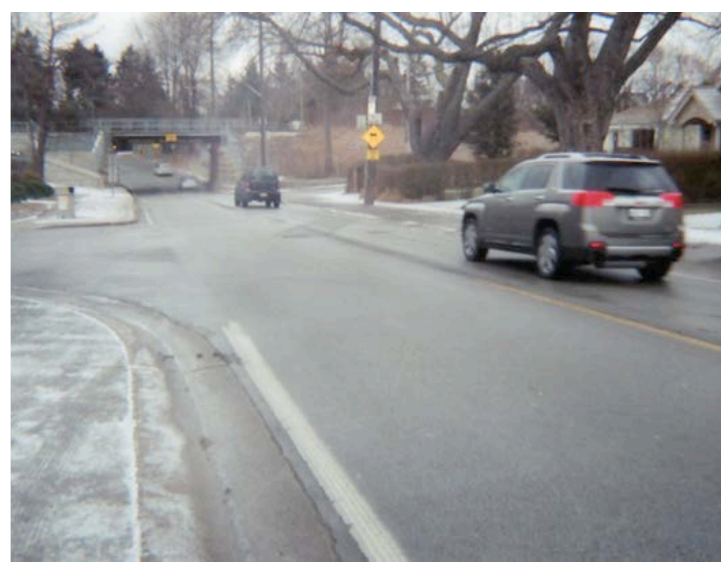

"I love walking down by the river. This crossing here is particularly treacherous. Sometimes the traffic comes way down here (past the bridge), there is a pathway here now that they have done recently (to the right of the picture, where the yellow sign is). There is no crossing between Indian Rd and Lakeshore. The new pathway you cross, takes you up by the river, memorial park. It is quite away and here it is not a safe place for anyone to cross because of the bend you can't really see." Jane, 67 


\subsection{Facilitators to Walking}

\subsubsection{Connection to Destinations}

All of the participating seniors walked for exercise. The major facilitator to walking among the seniors was walking routes that were connected to parks and trails with lots of green space that allowed them to see birds and squirrels.

As Carol, aged 60, who is an avid walker, stated:

"I tend to go to areas with a lot of greenery. Not just walking on concrete, so I tend to gravitate towards parks, if I am doing the urban walk and walking around Port Credit." April, 60

This was particularly evident amongst the seniors who lived in or near Port Credit, who stated that they enjoyed walking because they loved going to the parks by the water and enjoyed the quiet, scenic routes. And seniors, who did not live in the Port Credit area, enjoyed the parks and trails that were offered in their neighbourhood. Connection to such destinations was often emphasized.

\subsubsection{Amenities}

Seniors indicated features such as rails along sloping sidewalks, levelling of pavements and trails, the installation of cameras in parks with pathways or the removal of the bushes along a creek to open the park to the creek as ways in which to improve physical and personal safety concerns. 
Furthermore, a couple of seniors who use trails or parks as their main walking route, expressed the need for open and public washrooms, and more benches or ledges in which to set backpacks and relax for a few moments as important features to be included in their neighbourhoods. Patrick, aged 88, emphasized the importance of having places to sit, particularly benches as important features in his walking environment.

"(It would be nice if the city) rethink(s) the idea of the natural setting between the park (Applewood Hills Park) and the creek. Make the park open to the creek. It would be pleasant, if you put some benches alongside the creek. We are not stupid; we sit there and read a book. Instead, I am more inclined in the summertime to go to Lakeshore...I take a chair and a book to read down there." Patrick, 88

\subsubsection{Access}

Kim and Jane, two seniors who identified the inconvenient placement of crosswalks as barriers (Kim Quote and Figure 5), suggested point and cross crosswalks along road that have long stretches of no sidewalk. Kim believed that having such crosswalks might encourage people to walk more as they are able to walk across the street to grocery stores, drug stores, or bank and without having to worry or take their car. 


\section{Summary}

The findings from the research study indicate a number of barriers exist for seniors walking in their neighbourhood in Mississauga. Participating seniors' mentioned safety, both fall and traffic hazards as major concern when walking. Particularly, seniors identified the deteriorating sidewalks and trails, and a lack of snow clearing as potentially contributing to the risk of fall. Busy traffic conditions were also a barrier to walking. Seniors expressed concern regarding the placement of strip malls adjacent to busy roads presenting dangerous walking conditions and sometimes deterred individuals from walking along a sidewalk. Additionally, seniors felt the long distance between cross walks was a barrier when trying to reach shops and other amenities. To address safety concerns when walking, seniors' suggested the addition of rails along sloping sidewalks, levelling of pavement and trials, installing cameras in parks and removing bushes along a creek in a park. Furthermore, to address the inconvenient placement of crosswalks, seniors suggested installing point and cross crosswalks along heavy traffic roads to reach their desired locations safely. All participants enjoyed walking along trails and in parks. Although majority of seniors walked for exercise, quiet, scenic routes that are closer to nature was often emphasized as an important factor when choosing to where to walk. 


\section{Chapter Five: Discussion}

The sample of seniors who participated in this study were motivated and engaged throughout the process. They considered being physically active as one of the most important aspects of their daily life and were involved in multiple forms of exercise. All participants enjoyed walking and often walked as a form of exercise.

Several of themes emerged from the findings that were consistent with studies that have focused on exploring barriers seniors encounter when walking. These include: safety related to fall and traffic hazards. Although all participants walked on a regular basis, five out of the nine participants (55\%) stated that seasonality does have an effect on how often they walk. Several seniors stated presence of ice patches and snow piles often deterred them from walking outside. The findings from the study indicate that continuous and well-maintained sidewalks, trails, and pathways are of upmost importance for older adults; similar findings were reported elsewhere (Brownson et al, 2000). Previous studies also found that older people living in the neighourhoods with access to parks and other recreation spaces generally have higher levels of physical activity (Chaudhury et al 2012; Lockett et al, 2005; Giles-Corti et al, 2003; Booth et al, 1997). Although the findings from this study cannot adequately assess whether individuals with low access to parks walked less, majority of seniors mentioned the importance of available parks, trails and aesthetic features such as body of water, as one of the major facilitators to their walking. 
Furthermore, an important finding is the relationship between the location of a strip mall and the entry and exist points, as well as distance between crosswalks for elderly walking. Although the latter has emerged from previous studies (Chaudhury et al, 2012; Lockett et al, 2005), sidewalks adjacent to busy strip malls has not. This finding is particularly important for the suburban communities such as the City of Mississauga, where there is a higher prevalence of large smart centres and strip malls in neighbourhoods. Solutions to improve potential unsafe walking environments include, traffic calming measures, and creating buffers (street trees, shrubs, and street parking) to segregate pedestrians from the road. To address long distances between crosswalks, mid-block crossing between major intersections can encourage walking in surrounding neighbourhoods. Personal safety was a concern among a few seniors. These participants spoke to the fact that although their neighbourhood was safe due to preference they did not walk at night.

Unlike previous studies (Lockett et al, 2005) that have indicated the need for additional public washrooms and benches as recommendations improve the walking environment, most of participants did not speak to the importance of such amenities during their daily walks. These findings may be attributed to the time period in which the study took place. During the winter months seniors who walk most likely would not consider sitting on a bench for long periods of time.

Several studies have spoken to the importance of neighbourhoods with a mix of uses and facilities, such as proximity to grocery stores, banks and other local facilities, to 
promoting walking (Pikora et al, 2005; Berke et al, 2003; Ball et al, 2001; Giles-Corti et al, 2000). Results from the research revealed majority of the participants did not regard the proximity to such amenities as relevant to whether or not they chose to walk. However, one senior mentioned that it would be ideal to be within walking distance to major stores. All participants drove such amenities and often cited health concerns as the main reason.

\subsection{Limitations of the study:}

This study took place between the months of January and February, as it focused on walkability of older adults in the winter conditions. Due to the temperature and conditions outside, it was difficult to recruit seniors. Many individuals expressed interest, however declined to participate stating they often walked indoors, primarily in malls or used indoor walking tracks. The small sample size combined with the fact that majority of the seniors were female and were in relatively good health limits the generalizability of the study. It was difficult to recruit men and individuals who required the use of walking aids for this study to diversify the sample of participants and to possibly gather more barriers that would be encounter by these sectors of the population. Furthermore, a few seniors took images of areas in their neighbourhood they considered to be barriers for other seniors with mobility issues or who use walking aids. Although useful, this information had to be excluded for this project as it sought to uncover barriers in the built environment for the participating senior. Finally, in order to discover whether barriers were clustered in areas around a neighbourhood, the researcher attempted to undertake a mapping exercise during the interviews. This exercise would enable 
participants to locate specific areas in which they took the images. However, because most seniors were unable to effectively communicate on a map the area in which they took the image, this activity could not be completed with all nine participants. 


\section{Chapter Six: Conclusion}

Previous studies in public health and urban planning have associated the built environment of a neighbourhood to physical activity levels and walking patterns of individuals. However, there is a lack of research that has explored the barriers seniors encounter when walking in their neighbourhood, particularly in winter months. It is essential to promote walking as a form of physical activity amongst seniors, who are more prone to adverse health issues. Walking provides an easy and accessible way to maintain good health and mobility.

This study has been able to shed some light on the walking conditions seniors experience in the winter when walking in the neighbourhoods of Port Credit, Erin Mills, Cooksville/Dixie, Clarkson/Lorne Park in the City of Mississauga. Some new findings emerged with respect to the walking conditions for older adults living in the suburban municipalities. For example, the location of strip malls adjacent to busy roads was identified as an important barrier to walking, which remained unaddressed in the previous studies. Another important finding from this research, although mentioned in other studies is the long distance between cross walks. Areas such as Highway 10, Mississauga Road, Lakeshore Road, and Truscott are where there is conflict of use between pedestrians and vehicles, due to the location of a strip mall, lack of cross walk to access stores, and finally lack of snow clearing to walk safely along the sidewalk. The City of Mississauga has a large number of strip malls along busy roads; as such it is 
vital for city planners to work alongside retail developers to ensure the proper placement of such strips malls and streetscape characteristics to ensure the safety of pedestrians.

Findings that were similar to previous studies indicate that seniors regard poor sidewalk condition or the unavailability of sidewalks, walking trails with potholes and discontinuous trails as some of the biggest barriers to walking in the winter. The use of photovoice allowed the researcher to understand the barriers in a specific geographical context, and identify the locations in the study area that had particularly poor walking conditions.

It is evident from the results the importance of taking into consideration the location of strip malls when planning communities. Such findings can contribute to the policy initiatives the Region of Peel and the City of Mississauga are currently considering. Following direction from the Region, the City of Mississauga has recently implemented OP polices that require all land use developments in the City to take into consideration the public health implications. As such, results warrant future research to clarify the influence the built environment and health. Finally, the findings from this research can contribute to the development of questions that can be included in an audit tool to assess the quality of other neighbourhood walking routes.

Additional research exploring this topic should be undertaken to further understand the features in the built environment that can inhibit or facilitate walking in neighbourhoods for seniors. As the population ages rapidly in the city, it is important for planners and 
public health policy makers to adequately assess the state of the environment to provide municipal and community level strategies to promote and increase walking as a form of physical activity. Future research should aim to recruit a larger and more diverse group of seniors from across the City of Mississauga. The study period should be longer, to allow for comparability between seasons. The gender related differences in walking levels and behaviour also remains a topic for future research. 


\section{Appendix 1: Interview Guide 1}

\section{Interview Guide:}

\section{Walking in the winter: A Qualitative Study to Identify Environmental Barriers Encountered by the Elderly Population.}

Thank you for participating in my study and taking pictures of areas in your neighbourhood that you feel are barriers to your walking.

This interview is the last part of this exercise. I will be asking you questions about you, your walking behaviour, and how this relates to your neighbourhood.

Engaging in regular physical activity amongst the elderly population is very important, as research suggests that inactive older adults have an increased risk of falling, and developing chronic health conditions. Walking provides an extremely easy way in which the older adult population can increase their physical activity levels to prevent falling and reduce negative health effects. This form of physical activity is seen as a key source that is often accomplished within one's neighbourhood, either for travel and/or recreation. As such, research has shown that a safe and accessible built environment plays a major role increasing physical activity, especially amongst the older adults population.

\section{Necessary Background Information}

Name:

Age

Major intersection

Living Arrangement (alone/family)

Speak any other language at home?

In what area of the city do you live?

\section{Level of physical activity}

How often do you walk?

How would you rate your physical activity level?

Does seasonality have an effect on your physical activity/walking?

\section{Behavioural}

What do you do when you walk? Prompts - recreation/leisure. Do you walk for physical activity?

Do you often walk alone? In a group?

What motivates you?

Have you experienced a fall/slip during one of your daily walks?

- If so, where did this happen - describe the situation. Did you happen to take an image of where this area?

What are some of the barriers?

(if they don't outwardly say that their external environment acts as a barrier) Does your neigbourhood act as a barrier) 


\section{Social Capital}

Does walking help you socialize more?

Do you think that having a social group would allow you to walk more?

\section{Neighbourhood}

Please generally describe your neighbourhood

(possible prompts - amenities, density, types of people that live nearby)

What are the types of things you like about your neighbourhood when you walk? Why?

What are the things about your neighbourhood that you don't like? Why?

(possible prompts - how comfortable (do you feel safe, hazard free) when walking in your neighbourhood?)

What changes do you feel could be made in your neighbourhood to make walking more enjoyable

\section{Photograph Questions}

1. Thank you taking all of the images. I was just wondering how you felt about the exercise.

a. How often do you walk the route you took images of

2. Using the printed images please describe each image, its location in context to your daily walking route and why you chose to include it.

a. What do you think about this place?

b. Does your perception of this place influence your choice to walk? Why is this image a barrier or enabler along your walking route? Can you reflect on how you feel when you encounter this barrier?

(Prompts - what type of feeling do you get when you walk in this area?)

3. What kinds of improvements would you like to see made to the identified barriers?

4. Is there anything else about the buildings, streets, or neighbourhood that you would like to speak to? 


\section{Bibliography:}

Aultman-Hall, L., Lane, D., \& Lambert R.R. (2009). Assessing Impact of Weather and Season on Pedestrian Traffic Volumes. Transportation Research Record: Journal of the Transportation Research Board, Transportation Research Board of the National Academies, Washington, (2182), 35-43.

Ball, K., Bauman, A., Leslie, E., \& Owen, N. (2001). Perceived Environmental Aesthetics and Convenience and Company are Associated with Walking for Exercise among Australian Adults. Preventative Medicine 33, 434-440.

Berrigan D., \& Troiano R.P. (2002). The association between urban form and physical activity in U. S. adults. American Journal of Preventative Medicine 23, 74-79.

Booth, M.L., Owen, N., Bauman, A., Clavisi, O., \& Leslie, E. (2000). Social-Cognitive and Perceived Environment Influences Associated with Physical Activity in Older Australians. Preventative Medicine 31, 15-22.

Booth, M.L., Bauman, A., Owen, N., \& Gore, C. (1997). Physical Activity Preferences, Preferred Sources of Assistance, and Perceived Barriers to Increased Activity among Physically Inactive Australians. Preventative Medicine 26, 131-137.

Bosselmann, P., Arens, E., Dunker, K., \& Wright, R. (1995). Urban Form and Climate Case Study Toronto. American Planning Association. Journal of the American Planning Association 61(2), 226-239.

Brownson, R.C., Housemann, R.A., Brown, D.R., Jackson-Thompson, J., King, A.C., Malone, B.R., \& Sallis, J.F. (2000). Promoting Physical Activity in Rural Communities: Walking Trail Access, Use, and Effects. American Journal of Preventative Medicine 18(3), 235-241.

CBC News (2007). Seniors in Canada. Acessed on April 12, 2013. Retrieved from http://www.cbc.ca/news/interactives/map-canada-seniors/

Canadian Fitness and Lifestyle Research Institute (2005). Barriers to physical activity. Physical activity monitor. Bulletin no.4, Ottawa, On in Active Living Coalition for Older Adults (1999). A blueprint for Action, for Active Living and Older Adults: Moving through the years. Accessed on April 12, 2013. Retrieved from http://www.alcoa.ca/e/projects/movyears.htm

City of Houghton (2002). City of Houghton Walkability/Pedestrian Plan. Accessed on April 12, 201 Retrieved from http://www.wintercities.com/Winter Cities Institute Resources.html

City of Mississauga (2013). About Mississauga: Weather. Accessed on April 12, 2013. Retrieved from http://www.mississauga.ca/portal/discover/weather 
City of Mississauga (2012). Focus on Mississauga: Central Erin Mills Major Node. Accessed on April 12, 2013. Retrieved from http://www5.mississauga.ca/research catalogue/H 17 FocusOnMississauga $2012 \mathrm{Ce}$ ntral Erin Mills.pdf

City of Mississauga (2009). 2006 Census Results: Ward 2 Profile. Planning and Building Department 6(2). Accessed on April 12, 2013. Retrieved from http://www5.mississauga.ca/research catalogue/E 8 Ward 2 Census Profile.pdf

City of Mississauga Heritage (2009). Cooksville. Accessed on April 12, 2013. Retrieved from http://www.heritagemississauga.com/page/Cooksville

City of Mississauga Data (1999). 1996 Census Profile Applewood. Accessed on April 12, 2013. Retrieved from http://www5.mississauga.ca/research_catalogue/A26_apple1.PDF

City of Toronto Social Development, Finance and Administration Division (2008). Toronto Seniors Demographic Snapshot 2006. Accessed on April 12, 2013. Retrieved from www.toronto.ca/demographics/pdf/seniors pres 2006 census nov08.pdf

Colman, R., \& Walker, S. (2004). The cost of physical inactivity in British Columbia. Victoria, BC: GPI Atlantic. In Chaudry, H., Mahood, A., Michael, L.Y., Campo, M., Hay, K., (2011). The Influence of neighbourhood residential density, physical and social environments on older adults' physical activity: An exploratory study in two metropolitan areas. Journal of Aging Studies 26, 35-43.

Chaudhury, H., Mahood, A., Michael, L.Y., Campo, M., \& Hay, K. (2011). The Influence of neighbourhood residential density, physical and social environments on older adults' physical activity: An exploratory study in two metropolitan areas. Journal of Aging Studies 26, 35-43.

Cunningham, G.O., \& Michael Y.L. (2004). Concepts guiding the study of the impact of the built environment on physical activity for older adults: a review of the literature. American Journal of Health Promotion. 18, 435-43.

Edwards, P., \& Mawani, A. (2011). Healthy Aging in Canada: a New Vision, A Vital Investment: A discussion brief prepared for the Federal, Provincial and Territorial Committee of Officials (Seniors). Accessed on April 12, 2013. Retrieved from http://www.phac-aspc.gc.ca/seniors-aines/publications/public/healthysante/vision/vision-bref/index-eng.php

Fitzpatrick, K., Brewer, A. M., \& Turner, S. (2006). Another Look at Pedestrian Walking Speed. Transportation Research Record: Journal of the Transportation Research 
Board, Transportation Research Board of the National Academies, Washington, (1982), 21-29.

Gallagher, E., \& Scott, J.V. (1997). The STEPS Project: Participatory Action Research to Reduce Falls in Public Places Among Seniors and Persons with Disabilities. Canadian Journal of Public Health 88(2), 129-133.

Giles-Corti, B., \& Donovan R.J. (2003). Relative Influences of Individual, Social Environmental, and Physical Environmental Correlates of Walking. American Journal of Public Health 93(9),1583-1589.

Government of Canada Statistics Canada (2012). Life expectancy at birth, by sex, by province. Accessed on April 12, 2013. Retrieved from http://www.statcan.gc.ca/tablestableaux/sum-som/l01/cst01/health26-eng.htm

Health Canada. (2002). Healthy Aging - Physical Activity and Older Adults. In Public Health Agency of Canada (2010). The Chief Public Health Officer's Report on the State of Public Health in Canada 2010: Chapter 3: The Health and well-being of Canadian Seniors. Acessed on April 12, 2013. Retrieved from http://www.phacaspc.gc.ca/cphorsphc-respcacsp/2010/fr-rc/cphorsphc-respcacsp-06-eng.php

Handy, S., Boarnet, M.G., Ewing, R., \& Killingsworth, R.E. (2002). How the Built Environment Affects Physical Activity: Views from Urban Planning. American Journal of Preventative Medicine 23 (2S), 64-73.

Hoehner, C.M., Brennan Ramirez, L.K., Elliott, M.B., Handy, S.L., \& Brownson, R.C. (2005). "Perceived and Objective Environmental Measures and Physical Activity Among Urban Adults". American Journal of Preventive Medicine, 28(2S2), 105-116.

Hoehner, C.M., Ivy, A., Ramirez, L.B., Meriweather, B., \& Brownson, R.C. (2006). How Reliably do Community Members Audit the Neigbhourhood Environment for Its Support for Physical Activity? Implications for Participatory Research. Journal Public Health Management Practice 12(3), 270-277.

King, A.C., Sallis, J.F., Frank, L.D., Saelens, B.E., Cain, K., Conway, T.L., Chapman, J.E., Ahn, D.K., \& Kerr, J. (2011). Aging in neighbourhoods differing in walkability and income: Associations with physical activity and obesity in older adults. Social Science and Medicine 73, 1525-1533.

Lockett, D., Willis, A., \& Edwards, N. (2005). Through Seniors' Eyes: An Exploratory Qualitative Study to Identify Environmental Barriers to and Facilitators of Walking. Canadian Journal of Nursing Research 37 (3), 48-65.

Larson, E.B., Wang, L., Bowen, J.D., McCormick, W.C., Teri, L., Crane, P., \& Kukull, W. (2006). Exercise is associated with Reduced Risk for incident dementia among persons 65 years of age and older. Annals of Internals Medicine 144(2), 73-81. 
Li, F., Fisher, J., Brownson, R.C., \& Bosworth, M. (2005). Multilevel modeling of built environment characteristics related to neighbourhood walking activity in older adults. Journal of Epidemiol Community Health 59, 558-564.

Lim, K., \& Taylor, L. (2004). Factors associated with physical activity among older people - a population-based study. Preventative Medicine 40, 33-40.

Martel, L., \& Menard, F.P. (2013). The Canadian Population in 2011: Age and Sex. Government of Canada: Statistics Canada. Accessed on April 12, 2013. Retrieved from http://www12.statcan.gc.ca/census-recensement/2011/as-sa/98-311-x/98-311x2011001-eng.cfm

Nagel, L. C., Carlson, E. N., Bosworth, M., \& Michael, L. Y. (2008). The Relation between Neighbourhood Built Environment and Walking Activity among Older Adults. American Journal of Epidemiology 168 (4), 461-468.

Neuman, W. Lawrence (2006). Social research methods: qualitative and quantitative approaches. 6th ed. Allyn \& Bacon

Patterson, P.K \& Chapman, N.J. (2004). Urban form and older residents' Service Use, Walking, Driving, Quality of Life, and Neigbhourhood, Satisfaction. American Journal of Health Promotion 19(1), 45-52.

Pikora, T.J., Giles-Corti, B., Knuiman, M.W., Bull, F.C., Jamrozik, K., \& Donovan, R.J. (2006). Neighbourhood Environmental Factors Correlated with Walking near Home: Using SPACES. Medicine and Science in Sports 38(4), 708-714.

Public Health Agency of Canada (2010). The Chief Public Health Officer's Report on the State of Public Health in Canada 2010: Chapter 3: The Health and well-being of Canadian Seniors. Accessed on April 12, 2013. Retrieved from http://www.phacaspc.gc.ca/cphorsphc-respcacsp/2010/fr-rc/cphorsphc-respcacsp-06-eng.php

Public Health Agency of Canada (2007). Healthy Aging in Canada: A New Vision, A Vital Investment. Accessed on April 12, 2013. Retrieved from http://www.phacaspc.gc.ca/seniors-aines/publications/public/healthy-sante/vision/vision-bref/indexeng.php

Region of Peel (2012). Update on Term of Council Priority \#11: Assess the impacts of the aging population on health and human services delivered. Accessed on April 12, 2013. Retrieved from http://www.peelregion.ca/council/agendas/pdf/rc-20120329/report$\underline{\text { he-a1.pdf }}$

Region of Peel (2011). Health Background Study: Development of a Health Background Study Framework. Accessed on April 12, 2013. Retrieved from http://www.peelregion.ca/health/resources/healthbydesign/our-initiatives.htm 
Region of Peel (2006). External Causes of Emergency Department Visits, Morbidity and Mortality. Accessed on April 12, 2013. Retrieved from

www.peelregion.ca/health/.../seniors.../extern-emerg-visits.pdf

Risser, R., Haindl, G., \& Stahl, A (2009). Barriers to senior citizens' outdoor mobility in Europe. European Journal on Aging 7, 69-80.

Scott, V, Peck, S, \& Kendall, P. (2004). Prevention of falls and injuries among the elderly: A special report from the Office of the Provincial Health Officer. Victoria: BC Ministry of Health Planning. In Edwards, P., Mawani, A (2011). Healthy Aging in Canada: a New Vision, A Vital Investment: A discussion brief prepared for the Federal, Provincial and Territorial Committee of Officials (Seniors). Retrieved from http://www.phac-aspc.gc.ca/seniors-aines/publications/public/healthysante/vision/vision-bref/index-eng.php

Shipp, K.M., \& Branch, I.G. (1999). Physical environment as a determinant of the health status of older populations. Canadian Journal Aging 18, 313-327.

Stahl, A., Carlsson, G., Hovbrandt, P., \& Iwarsson, S. (2008). "Let's Go for a Walk!": identification and prioritization of accessibility and safety measures involving elderly people in a residential area. European Journal Ageing 5, 265-273.

Statistics Canada (2009). CANSIM Table 105-0501 Health Indicator profile, annual estimates, by age group and sex, Canada, provinces, territories, health regions (2007 boundaries) and peer groups, occasional [Data File]. Accessed on April 12, 2013. Retrieved from http://www5.statcan.gc.ca/cansim/a05?lang=eng\&id=1050501. In Public Health Agency of Canada (2010). The Chief Public Health Officer's Report on the State of Public Health in Canada 2010: Chapter 3: The Health and well-being of Canadian Seniors. Retrieved from http://www.phac-aspc.gc.ca/cphorsphc-respcacsp/2010/frrc/cphorsphc-respcacsp-06-eng.php

Tencer, S. (2010). Contextualizing the Community Walkability Audit Tool. Retrieved from http://www.cleanairpartnership.org/active transportation

The Social Planning Council of Peel (2010). The Senior Population in Peel Region: Characteristics, Trends and Issues (1996-2006). Accessed on April 12, 2013. Retrieved from www.spcpeel.com/2010\%20seniors.pdf

The Weather Network (2013). Statistics: Mississauga, ON. Retrieved from http://www.theweathernetwork.com/statistics/CL6158733/caon0441

Toronto Rehab (2011) . +10 Report on Rehabilitation Research. Accessed on April 12, 2013. Retrieved from http://www.torontorehab.com/Research/Reports-and-

Brochures/Annual-Research-Reports/-10-Report-Online.aspx 
Toronto Rehab (2012). Winterlab. Accessed on April 12, 2013. Retrieved from http://www.torontorehab.com/Research/Facilities/Labs/WinterLab.aspx

Wang, C. C., Yi, K.W., Tao, W.Z., \& Carovano, K. (1998). Photovoice as a participatory health promotion strategy. Health Promotion International 13(1), 75-86.

Wang, C., \& Burris, M. (1994). Empowerment through Photo Novella: Portraits of Participation. Health Education Quarterly 21 (2), 171-186.

Weuve, J., Kang, J.H., Manson, J.E., Breteler, M.M., Ware, J.H., \& Grodstein, F. (2004). Physical Activity, including walking, and cognitive function in older women. Journal American Medical Association 292 (12), 1454-1461. 